\title{
ANÁLISE DE DESEMPENHO DOS SERVIÇOS DE UMA MICROEMPRESA SOB A PERSPECTIVA DA ESTRATÉGIA DE OPERAÇÕES
}

\section{PERFORMANCE ANALYSIS OF MICRO-BUSINESS SERVICES UNDER THE OPERATING STRATEGY PERSPECTIVE}

\author{
Alan Barreto Santos* E-mail: alanbts25@gmail.com \\ Richard Andres Estombelo Montesco*E-mail: restomb@academico.ufs.br \\ *Universidade Federal de Sergipe (UFS), São Cristóvão, SE
}

Resumo: O presente trabalho tem como objetivo analisar o desempenho, no âmbito operacional, de uma microempresa prestadora de serviços de instalação elétrica, automação residencial e predial, de modo a proporciona-la o direcionamento para a busca do alinhamento da estratégia de operações com a estratégia do negócio. Uma estrutura metodológica foi proposta, sendo composta sequencialmente pelo: mapeamento de processos; análise de importância e desempenho a partir da aplicação da matriz IPA; construção da matriz de relação; e proposição de um sistema de indicadores e plano de ação. Este estudo permitiu a identificação de um conjunto de fatores pelos quais os clientes avaliam o desempenho da empresa, além de sua avaliação em relação a estes fatores. Destaca-se o bom desempenho no fator conformidade, apesar do baixo desempenho em um conjunto de outros fatores, destacando dentre estes o fator preço. Um dos indicadores propostos possibilitou explicitar o desempenho negativo da empresa no ano analisado, e a partir da utilização de algumas ferramentas da qualidade, foi possível elaborar um plano de ação para que a empresa possa utilizar como ponto de partida na busca por melhorias em diferentes contextos do negócio.

Palavras-chave: Estratégia de operações. Mapeamento de processos. Matriz IPA. Microempresa. Sistema de indicadores de desempenho.

\begin{abstract}
The present work has the objective of analyzing the performance, in the operational scope, of a microenterprise that provides electric installation, residential and building automation services, to provide a direction to search for the alignment between operations and business strategies. A methodological proposed: process mapping, analysis of the matrix importance performance with correlation, suggestion of indicators and action plan. This study allowed the identification of a set of factors by which customers evaluate the company's performance. It was noticed a good performance in the compliance factor, but a low performance in a set of other factors, among which the price factor. One of the proposed indicators made explicitly possible or the company's negative performance in the year analyzed, and using some quality tools, it was possible to elaborate an action plan for the company to use as a starting point in the search for improvements in different business contexts.
\end{abstract}

Keywords: Operations strategy. Mapping processes. IPA Matrix. Micro enterprise. System of performance indicators.

\section{INTRODUÇÃO}

As Micro e Pequenas Empresas (MPE) são fundamentais durante períodos de turbulências na economia de uma nação, sendo que estes empreendimentos favorecem a redução do desemprego (IBGE, 2003). 
No ano de 2014, o Serviço Brasileiro de Apoio às Micro e Pequenas Empresas (SEBRAE) e a Unidade de Gestão Estratégica (UGE) mostraram que no ano de 1985, as MPEs representavam cerca de $21 \%$ do Produto Interno Bruto (PIB) nacional, passando para $23 \%$ em 2001 e chegando a atingir cerca de $27 \%$ em 2011. O pequeno negócio é muito importante, pois ele leva ao aumento da oferta de empregos, novos produtos são desenvolvidos, determinadas populações são atendidas, há autonomia e aumento da riqueza por parte dos empreendedores, entre outras contribuições.

Contudo, ao analisar o tempo de vida dos pequenos negócios, o Instituto Brasileiro de Planejamento e Tributação (IBPT, 2013) concluiu que aproximadamente $44,95 \%$ das micro e pequenas empresas entram em falência nos primeiros cinco anos de vida.

Vários estudos foram realizados a fim de identificar as possíveis causas desta alta taxa de mortalidade, mas não existe atualmente um estudo definitivo, e os resultados das pesquisas mostram diferentes fatores. Como exemplos, pode-se citar as competências gerenciais, alta concorrência, falta de planejamento e de informações do mercado, complexidade tributária e burocracias e dificuldade no acesso a crédito financeiro e a investimentos (FATOKI, 2014; FERREIRA, 2012; IBPT, 2013).

O setor de serviços vem crescendo, tanto no âmbito nacional quanto mundial, sendo que no ano de 2015, este setor teve uma receita operacional líquida de aproximadamente 1,4 trilhão de reais somente no Brasil e empregou mais de 12,7 milhões de pessoas em todo Brasil (IBGE, 2015). As micro e pequenas empresas vêm contribuindo fortemente para o setor de serviços, sendo que estas representam aproximadamente $36,3 \%$ do PIB deste setor (SEBRAE; UGE, 2014).

O presente trabalho tem como objetivo avaliar o desempenho das operações de uma microempresa que atua na prestação de serviços de instalação e manutenção elétrica e de automação residencial, permitindo-a direcionar suas operações na busca pelo atendimento de seus objetivos estratégicos.

A alta concorrência é um fator presente na maior parte dos segmentos de mercado, e está presente no dia a dia dos pequenos negócios. Para que um negócio possa se manter, é preciso se diferenciar em algum aspecto, e isso pode ser realizado por meio da gestão de produção e operações, que permitem a formulação 
de estratégias de operações que contribuem fortemente para a estratégia de um negócio, impactando no potencial competitivo da empresa (PAIVA; CARVALHO JÚNIOR; FENSTERSEIFER, 2004).

A empresa analisada não possui nenhuma ferramenta de auxílio à gestão operacional do negócio. Verificou-se também que a empresa não realizou, em nenhum momento, pesquisa de avaliação de desempenho sob a perspectiva dos clientes. Não há planejamento formalizado e tampouco são utilizadas métricas ou procedimentos para análise dos resultados das operações do negócio. Segundo Diaz (2007), cerca de $60 \%$ dos casos de falência das micro e pequenas empresas em até quatros anos de operação ocorrem devido à má gestão empresarial e falta de métricas que possibilitem o monitoramento do desempenho do negócio.

Verifica-se então a importância de uma investigação acerca do desempenho atual do negócio sob a perspectiva da estratégia de operações. É essencial o desenvolvimento de sistemas de indicadores para micro e pequenas empresas com foco na tradução das suas estratégias em medidas que explicitem a saúde do negócio, e que permitam ainda monitorar sua evolução no decorrer do tempo. O uso de indicadores como apoio à gestão do negócio pode resultar em ganhos como satisfação dos clientes, aumento da eficiência operacional e melhoria da qualidade de produtos e serviços, gerando impacto positivo no faturamento da empresa, entre outros benefícios (DIAZ, 2007).

\section{REFERENCIAL TEÓRICO}

Esta seção está dedica a expor alguns dos principais conceitos contidos na literatura acadêmica sob as ferramentas, técnicas, metodologias e abordagens inerente as propostas deste estudo. É necessário também destacar algumas das particularidades do cenário atual que envolve a empresa investigada.

\subsection{Panorama das Micro e Pequenas Empresas (MPE)}

A Lei geral é um Estatuto Nacional destinado ao Microempreendedor Individual (MEI), Microempresa (ME) e Empresas de Pequeno Porte (EPP), instituída pela Lei Complementar № 123, de 14 de dezembro de 2006, de forma a fornecer um 
tratamento diferenciado, com um maior grau de simplificação, e assim favorecer esse setor por meio de normas gerais que atuam no âmbito dos poderes da União, dos Estados, do Distrito Federal e dos municípios, nos termos dos artigos 146, 170 e 179 da Constituição Federal (BRASIL, 2006).

Por meio da Lei geral, foi instituído o Simples Nacional ou Supersimples que se trata de um regime tributário específico que pode ser aplicado somente as $M E$, MEI e EPP, gerando alguns benefícios como a redução da carga de impostos, a simplificação e desburocratização do recolhimento de impostos (BRASIL, 2006; SEBRAE, 2016). Decorrente disso, surgem outras facilidades como o acesso ao crédito, aos mercados, a participação em licitações, simplificação das relações trabalhistas, fiscalização, além de estimular a inovação e a exportação, aquecendo assim, a economia do país (SEBRAE, 2016).

O Simples Nacional trata-se de um regime especial de tributação, instituído pela Lei Geral - Lei Complementar n 123, de 14 de dezembro de 2006, que implica no recolhimento mensal, por documento único de arrecadação, de vários impostos e contribuições (BRASIL, 2006). A Receita Federal (2017) afirma que os pontos positivos do Simples Nacional são optativos, primeiramente, e então irretratável durante $O$ ano-calendário. Os tributos contemplados por esse regime são: IRPJ, CSLL, PIS/Pasep, COFINS, IPI, ICMS, ISS, CPP. Para recolhimento destes tributos utiliza-se o Documento de Arrecadação do Simples Nacional (DAS), além disso, deve-se apresentar declaração única e simplificada de informações socioeconômicas e fiscais.

Quando uma empresa decide ser optante pelo Simples Nacional, esta precisa estar classificada dentre uma das três subcategorias pertencentes às MPE, tais como mostrado no Quadro 1, sendo estas: MEI; ME; EPP.

No Brasil, ano 2000, a porcentagem de micro e pequenas empresas sobre o total de empresas prevaleceu no intervalo de 83,91 \% a 97,15 \%. Em 2004 essa porcentagem variou entre $76,25 \%$ a $90,27 \%$ (VIEIRA, 2007). O crescimento das Micro e pequenas empresas vem aumentando nos últimos anos, isso implica em maior participação desse setor na economia brasileira. 
Quadro 1 - Classificação para as MPE

\begin{tabular}{|l|l|c|}
\hline \multicolumn{1}{|c|}{ Classificação } & \multicolumn{1}{c|}{ Natureza jurídica } & Receita bruta anual \\
\hline $\begin{array}{l}\text { Empresa de pequeno } \\
\text { porte (EPP) }\end{array}$ & $\begin{array}{l}\text { Sociedade empresária, Sociedade } \\
\text { simples, Empresa individual de } \\
\text { responsabilidade limitada (EIRELI); } \\
\text { Empresário individual }\end{array}$ & $\begin{array}{c}\text { Superior a } \\
\mathrm{R} \$ 360.000,00 \\
\text { e igual ou inferior a } \\
\mathrm{R} \$ 4.800 .000,00^{*}\end{array}$ \\
\hline Microempresa (ME) & $\begin{array}{l}\text { Sociedade empresária, Sociedade } \\
\text { simples, Empresa individual de } \\
\text { responsabilidade limitada (EIRELI); } \\
\text { Empresário individual }\end{array}$ & $\begin{array}{c}\text { Igual ou inferior a } \\
\mathrm{R} \$ 360.000,00\end{array}$ \\
\hline $\begin{array}{l}\text { Microempreendedor } \\
\text { individual (MEI) }\end{array}$ & Empresário individual & $\begin{array}{l}\text { Igual ou inferior a } \\
\mathrm{R} \$ 81.000,00^{*}\end{array}$ \\
\hline
\end{tabular}

${ }^{*}$ a partir de $1^{\circ}$ de janeiro de 2018.

Fonte: (BRASIL, 2006, 2016)

O pequeno negócio é geralmente relacionado ao empreendedorismo, mas é preciso distinguir as iniciativas empreendedoras, do pequeno negócio já formalizado. O processo de idealização empreendedora funciona a partir da criatividade e motivação (BAGGIO; BAGGIO, 2014). O pequeno negócio surge de uma iniciativa empreendedora, em que o empreendedor identifica uma oportunidade e implementa esforços e recursos, de modo a desenvolver um negócio podendo ser algo tradicional (já conhecido), com particularidade distintas ou totalmente inovador.

O Brasil é considerado um país com característica empreendedora, sendo que o mesmo ocupa a 15 a posição do Ranking do Empreendedorismo por Oportunidades e a 4⿳亠丷厂 posição no Ranking do Empreendedorismo por Necessidades (BAGGIO; BAGGIO, 2014).

A taxa de empreendedorismo no Brasil em 2014 era de 34,4 \% e em 2015 essa taxa aumentou para $39,4 \%$. Isso mostra um crescimento de $4,9 \%$ do total de empreendimentos entre os anos de 2014 e 2015 (GEM, 2015).

\subsection{Técnicas e ferramentas de melhorias em serviços}

O mapeamento de processos constitui uma das primeiras e principais etapas para buscar a otimização dos processos de um negócio, seja indústria ou serviço. De acordo com Baldam et al. (2007) os processos constituem num conjunto de atividades, que atuam de forma interativa, transformando entradas em saídas, de modo que agreguem valor a um determinado público.

Os autores Baldam et al. (2007) e Pavani Júnior e Scucuglia (2011) afirmam que a abordagem Business Process Management (BPM) corresponde a uma das 
principais metodologias para implementação da Gestão por Processos, sendo referência para muitas das ferramentas utilizadas no cenário atual. A linguagem contida nesta metodologia é a Business Process Management Notation (BPMN), que é amplamente difundida e de fácil compreensão, podendo ser aplicada a todos os tipos de modelagem (PAVANI JÚNIOR; SCUCUGLIA, 2011).

Além do mapeamento de processos, as ferramentas Matriz de correlações e $5 \mathrm{~W} 2 \mathrm{H}$ são amplamente difundidas no meio acadêmico, para a busca por melhorias da qualidade em produtos e serviços.

A Matriz de relações é utilizada para avaliar as relações e suas intensidades entre diversas variáveis. Uma das suas principais aplicações encontra-se na casa da qualidade do Quality Function Deployment (QFD, Desdobramento da Função Qualidade), em que se pode comparar as relações de requisitos da qualidade com requisitos do projeto. Contudo, existem diversas formas de aplicações desta matriz, segundo Carpinetti (2010) pode-se utilizá-la para comparar as relações entre um grupo de determinadas característica de um bem ou serviço, sendo que nesses casos essa matriz é denominada de matriz de correlações.

A Figura 1 mostra uma representação para a aplicação da matriz de relações (ou matriz de correlações) para alguns requisitos do projeto de um determinado produto.

Figura 1 - Exemplificação da aplicação da Matriz de correlações

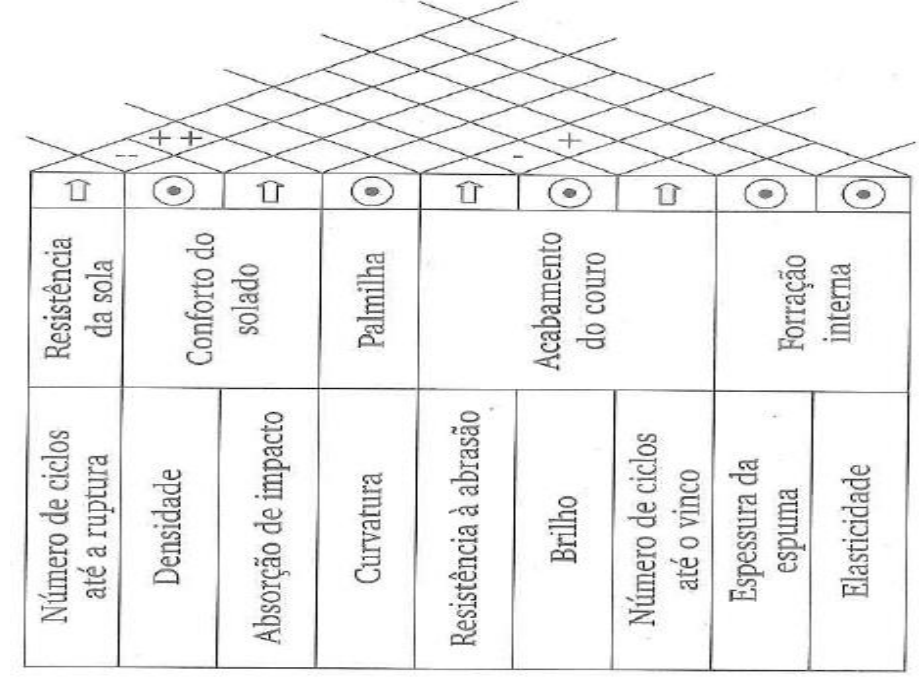

Fonte: Carpinetti (2010, p. 103) 
A partir da Figura 1 pode-se observar que cada requisito é comparado com os demais, utilizando para isso, quatro tipos de intensidades de relação. A relação "Muito negativo" implica, para dois requisitos comparados, que a busca por melhoria em um destes influenciará de forma altamente negativa no outro. A relação "Negativo" é similar a relação "Muito negativo", porém com menor intensidade, este é o caso da relação entre o requisito "Peso" com os requisitos "Resistência à fadiga" e "Resistência ao impacto" (CARPINETTI, 2010).

A relação "Positivo" tem sentido oposto as duas relações anteriores, neste caso um determinado requisito quando comparado com um outro possui este tipo de relação, diz-se que um influencia moderadamente de forma positiva no outro, como acontece entre os requisitos "Resistência à fadiga" e "Resistência a corrosão". Do mesmo modo acontece com a relação "Muito positivo", mas com um sentido de intensidade superior a relação anterior (CARPINETTI, 2010). Há casos em que dois requisitos não possuem nenhum tipo de relação, sendo que a alteração de um não influenciará de nenhum modo no outro, este é o caso do requisito "Resistência a corrosão" com todos os demais.

A ferramenta 5W2H (What, Who, Where, Why, How e How much) consiste numa ferramenta de cunho estratégico que auxilia no planejamento de atividades de um negócio. Basicamente, representa um plano de ação bem detalhado, que explicita atividades, descrições e responsabilidades, formando assim, um modelo padrão, o que pode vir a favorecer e complementar um processo de diagnóstico e intervenções de um negócio (LISBOA, 2009). A Figura 2 mostra a estrutura que compõe a ferramenta $5 \mathrm{~W} 2 \mathrm{H}$.

Figura 2 - Estrutura da ferramenta 5W2H

\begin{tabular}{|l|c|c|c|c|c|c|}
\hline $\begin{array}{c}\text { O que? } \\
\text { (What) }\end{array}$ & $\begin{array}{c}\text { Quem? } \\
\text { (Who) }\end{array}$ & $\begin{array}{c}\text { Onde } \\
\text { (Where) }\end{array}$ & $\begin{array}{c}\text { Quando? } \\
\text { (When })\end{array}$ & $\begin{array}{c}\text { Por quê? } \\
\text { (Why) }\end{array}$ & $\begin{array}{c}\text { Como? } \\
\text { (How })\end{array}$ & $\begin{array}{c}\text { (Quanto?) } \\
\text { (How much) }\end{array}$ \\
\hline Ação 1 & & & & & & \\
\hline Ação 2 & & & & & & \\
\hline
\end{tabular}

Fonte: Adaptado de Lisboa (2009)

Na Figura 2, a coluna "O que?" representa as ações que serão tomadas ou o que será feito. A coluna "Quem?" corresponde ao indivíduo ou grupo de indivíduos a quem pertence a responsabilidade pela realização das ações contidas na coluna anterior (LISBOA, 2009). Em “Onde?”, encontra-se o local em que estas ações serão 
realizadas, enquanto "Quando?", refere-se ao período previsto para início e término das atividades que compõe as ações. Na coluna "Por quê?" atribui-se os motivos pelos quais as ações são necessárias, e em "Como?" concede os meios utilizados para realização das ações, como as atividades, os métodos e processos (LISBOA, 2009). E finalmente, a coluna "Quanto?" refere-se ao valor necessários para custear gastos e despesas decorrentes da realização das ações propostas (LISBOA, 2009).

\subsection{Estratégia de Operações (EO)}

De acordo com Paiva, Carvalho Júnior e Fensterseifer (2004) a estratégia de operações consiste na estratégia a nível operacional de um negócio, a qual deve estar alinhada com a estratégia de negócios, de modo a enfatizar nas decisões relativas aos objetivos e atividades da produção. A estratégia de operações pode ser traduzida através de cinco objetivos de desempenho, sendo estes: Confiabilidade; Qualidade; Flexibilidade; Velocidade e Custo (SLACK; CHAMBERS; JOHNSTON, 2009). Estes objetivos são descritos como:

- Confiabilidade: consiste em entregar os produtos ou serviços no tempo esperado pelos consumidores, ou mais precisamente no tempo prometido, sendo que este objetivo é avaliado apenas após a entrega do bem (PAIVA; CARVALHO JÚNIOR; FENSTERSEIFER, 2004; SLACK; CHAMBERS; JOHNSTON, 2009);

- Qualidade: consiste em um conjunto de características atribuídas a um produto ou serviço, de forma a proporcionar satisfação aos consumidores, facilidades motivações aos clientes internos e menor impacto ambiental possível (CARPINETTI, 2010);

- Flexibilidade: capacidade da empresa em se adaptar ao ambiente em que está inserida, ou seja, de reagir tanto no contexto interno quanto no externo (PAIVA; CARVALHO JÚNIOR; FENSTERSEIFER, 2004);

- Velocidade: dita como o intervalo de tempo entre o pedido dos produtos ou serviços até a entrega dos mesmos aos consumidores (SLACK; CHAMBERS; JOHNSTON, 2009); 
- Custo: segundo Paiva, Carvalho Júnior e Fensterseifer (2004) uma das formas de competitividade, através da estratégia da produção, é com a ênfase na redução de custos da produção. O foco é buscar a ampla minimização dos custos envolvidos na produção ou realização das operações, sendo que a empresa pode optar por reduzir os preços dos bens e serviços, e assim, aumentar seu potencial competitivo. Existe também, a opção de não transferir esta redução de custo para os preços dos bens e serviços, que leva ao aumento da margem operacional, e como consequência, poderá haver maior lucro líquido.

Deve ressaltar que a estratégia de operações se preocupa com a função produção no longo prazo, analisando processos produtivos globais e não de forma individualizada, e ainda seu relacionamento com outras funções do negócio (CORRÊA; CAON, 2002).

\subsection{Avaliação de desempenho}

O processo de mensuração de desempenho consiste em identificar as principais variáveis de um negócio que devem ser mensuradas, ou seja, aquelas consideradas mais importantes, de forma a transmitir essas informações para todos os envolvidos no negócio, que impulsionará na motivação dos mesmos, permitindo ainda, o fornecimento de feedback para a tomada de decisões e consequentemente poder levar a empresa na busca por melhorias (JOHNSTON; CLARK, 2002).

De acordo com Martilla e James (1977) o desempenho de uma empresa pode ser julgado por meio da análise importância-desempenho (Importance Performance Analysis, IPA), desenvolvida por estes autores, ao qual consiste em comparar a importância de determinados fatores para os clientes com o desempenho da empresa em relação a estes fatores. Tanto a avaliação da importância quanto do desempenho é realizada pelo cliente, geralmente por meio de questionários. Estes fatores são chamados fatores competitivos, pois, comumente agregam valor aos olhos do cliente final.

Geralmente dois questionários são aplicados, há casos em que apenas um questionário é aplicado, sendo o primeiro é destinado a verificação do Grau de 
Importância médio $(\overline{G I})$ de cada fator, por meio de uma frase ou uma pergunta que descreva o mesmo, enquanto que o segundo é direcionado para a avaliação da percepção que cada cliente possui, em relação a cada fator, sobre o desempenho da empresa nestes fatores. Assim, esse segundo questionário tem por propósito, permitir a obtenção do Grau de Desempenho médio $(\overline{G D})$, que juntamente com o $\overline{G I}$, possibilitará a plotagem de uma matriz bidimensional (MARTILLA; JAMES, 1977). Este, é composto pelos eixos " $X$ " (onde são inseridos os valores de desempenho) e "Y" (contempla os valores de importância). Os procedimentos de cálculo para o $\overline{G I} \mathrm{e}$ $\overline{G D}$, respectivamente, são representados pelas Equações (1) e (2).

$$
\overline{G I}=\frac{\sum_{i}^{m} G I_{i j}(X)}{m}
$$

$$
\overline{G D}=\frac{\sum_{i}^{n} G D_{i j}(X)}{m}
$$

Onde,

Glij $(X)$ - é o Grau de Importância do fator $j$, segundo a percepção de um determinado cliente $i$, com $i=1,2, m$;

GDij $(X)$ - é o Grau de Desempenho dos serviços ou produtos referentes ao fator $j$, de acordo com o cliente $i$; $\mathrm{m}$ - número de respondentes.

Através da análise IPA, pode-se construir a matriz bidimensional constituída por quatro quadrantes, como mostra a Figura 3. Nessa matriz são plotados os valores de Grau de Importância e de Grau de desempenho dos fatores. 
Figura 3 - Matriz importância-desempenho

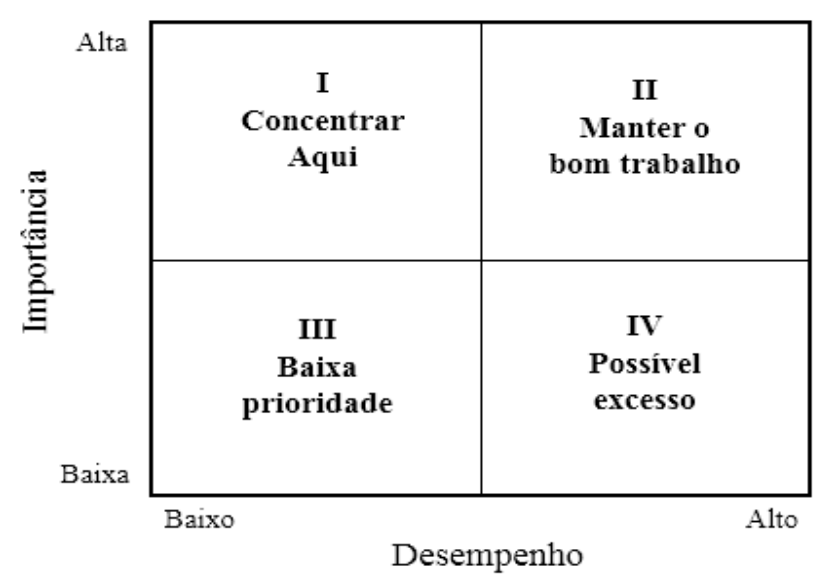

Fonte: Adaptado de Martilla e James (1977); Freitas e Moraes (2012)

I. Concentrar aqui: os fatores localizados neste quadrante são classificados como prioritários, devido à alta importância para os clientes e baixo desempenho nestes fatores, por parte da empresa;

II. Manter o bom trabalho: neste quadrante, concentram-se os fatores que representam a força atual da empresa, pois possuem alta importância aos olhos dos clientes e têm tido bom desempenho, por parte da empresa, ainda sob a ótica deste público. Neste caso, as iniciativas e ações realizadas devem ser mantidas, de modo a manter o bom desempenho;

III. Baixa prioridade: no terceiro quadrante, pode-se identificar os fatores irrelevantes para o negócio, devido à baixa importância para os clientes, e a não aplicabilidade de grandes esforços, o que deve ser mantido;

IV. Possível excesso: consiste no quadrante que envolve os fatores de baixa importância, mas que possui esforços em excesso. Assim, é intuitivo que a empresa busque direcionar esse excesso para outros fatores que possuam maior importância para os clientes, e que não estão tendo desempenho suficiente, por parte da empresa, como os fatores localizados no quadrante I.

Contudo, diversos autores têm realizado modificações na matriz tradicional, para avaliar serviços, em que o público alvo geralmente possui uma tendência a atribuir altos valores de importância, e também de desempenho aos fatores, o que os leva, na maioria dos casos, a cair no quadrante II. De acordo com Freitas e 
Morais (2012), essas quatro regiões podem ser obtidas por meio das médias globais de importância $(\overline{G I}(x))$ e de desempenho $(\overline{G D}(x))$, como mostra as Equações (3) e (4), e permite realizar uma análise bastante rígida, e assim, apoiar o processo decisório de uma prestadora de serviços.

$$
\begin{aligned}
& \overline{G I}(x)=\frac{\sum_{j=1}^{n} \sum_{i=1}^{m} G I_{i j}(x)}{n * m} \\
& \overline{G D}(x)=\frac{\sum_{j=1}^{n} \sum_{i=1}^{m} G D_{i j}(x)}{n * m}
\end{aligned}
$$

Onde,

$\mathrm{n}$ - número de fatores ou variáveis avaliadas;

$\mathrm{m}$ - número de respondentes dos questionários.

Estas médias permitiram o deslocamento dos eixos, que indicaram as quatro regiões descritas anteriormente. Além disso, os autores Tarrant e Smith (2002) apud Freitas e Morais (2012) destacam a necessidade do uso e plotagem do erro padrão para a importância e desempenho de cada fator. Estes erros facilitarão a tomada de decisão em casos em que um determinado fator se encontra na linha de fronteira entre duas regiões. As Equações (5) e (6) calculam o intervalo de confiança da importância $\left(I C_{G I(x)}\right)$ e do desempenho $\left(I C_{G D(x)}\right)$ para cada fator, respectivamente.

$$
\begin{aligned}
& I C_{G I(x)}=\overline{G I}(x)_{j} \pm \frac{S_{G I(x) j}}{\sqrt{n}} \\
& I C_{G D(x)}=\overline{G D}(x)_{j} \pm \frac{S_{G D(x) j}}{\sqrt{n}}
\end{aligned}
$$

$S_{G I(x) j}$ e $S_{G D(x) j}$ representam os desvios padrão para a importância e desempenho de cada fator avaliado, respectivamente.

\section{PROCEDIMENTOS METODOLÓGICOS}

O tipo de pesquisa utilizado foi a pesquisa exploratória em conjunto com procedimentos de Estudo de caso. De acordo com Gil (2008) é neste tipo de 
pesquisa que ocorre uma maior familiaridade do pesquisador com os fatos investigados. A pesquisa exploratória não necessita de planejamento detalhado, sendo bastante utilizada quando o tema escolhido é pouco explorado, em que há dificuldade na construção de hipóteses.

Para levantamento dos dados, foram utilizadas as pesquisas bibliográfica e documental, como a documentação indireta. A pesquisa bibliográfica permite, a partir de material já publicado, a profunda investigação sobre grande diversidade de fatos (GIL, 2008). A pesquisa documental é semelhante a pesquisa bibliográfica, diferindo apenas na natureza das fontes, pois a pesquisa documental utiliza-se de material que não recebeu tratamento analítico (GIL, 2008).

\subsection{Estrutura metodológica proposta}

Foram elaboradas 3 etapas necessárias para o alinhamento entre a estratégia de operações com a estratégia da empresa. Essas etapas estão resumidas na Figura 5 e descritas em seguida.

Figura 5 - Estrutura metodológica proposta

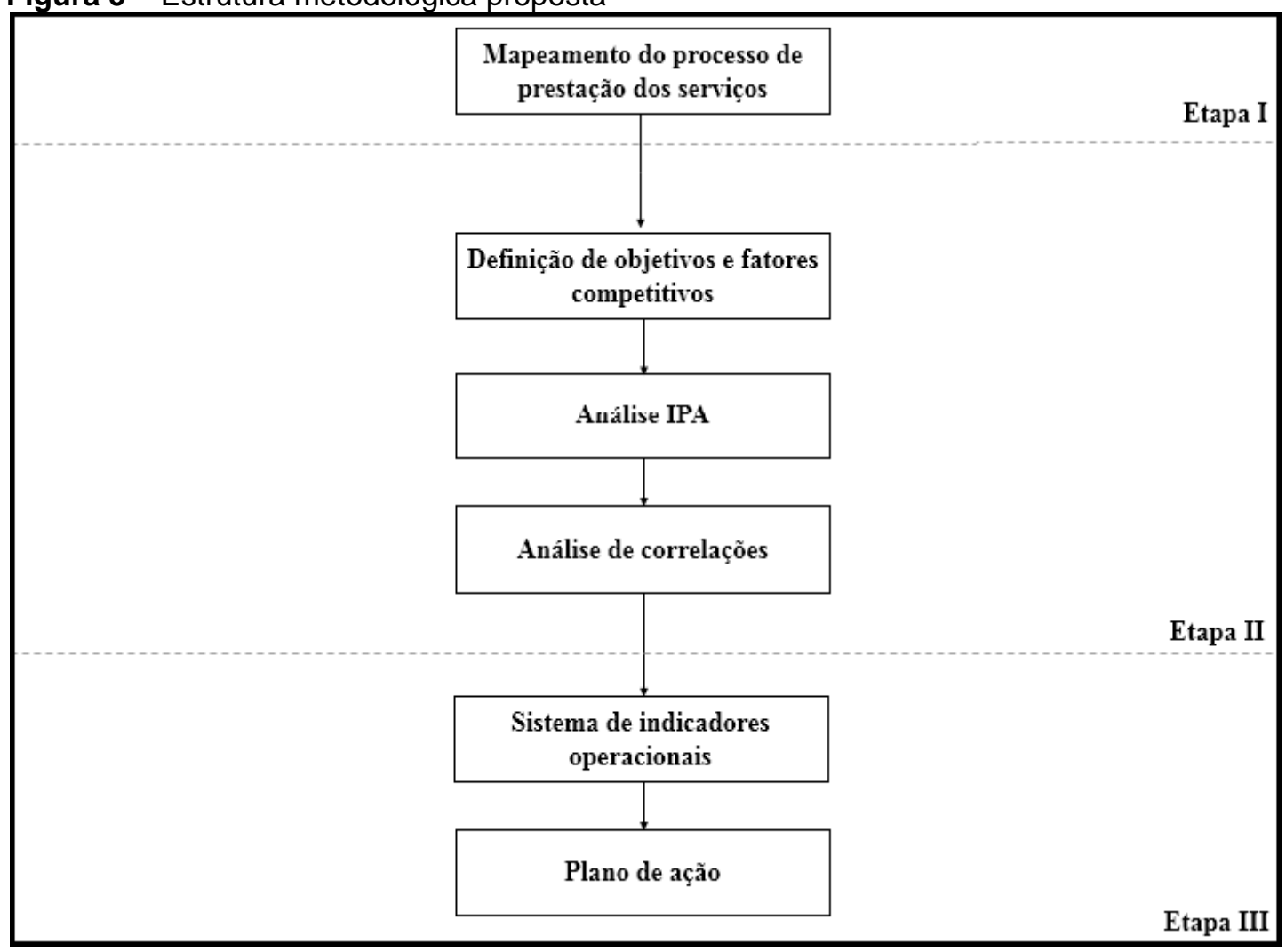

Fonte: $\mathrm{O}$ autor 
Com base na Figura 5 é perceptível que a estrutura metodológica é composta basicamente por três etapas, sendo estas:

- Etapa I: consiste em mapear os fluxos, atividades e pontos de decisão intrínsecos ao processo de prestação de serviços da empresa sob uma perspectiva geral. O resultado do mapeamento de processos é essencial, pois permite o levantamento de informações relevantes e auxilia nas etapas subsequentes;

- Etapa II: utilizando o modelo de cinco objetivos de desempenho de Slack, Chambers e Johnston (2009), o mapeamento de processos, e os estudos de Johnston e Clark (2002) e Corrêa e Caon (2002), foi possível converter estes objetivos em fatores competitivos para empresas atuantes no segmento de serviços. Definidos os fatores competitivos, aplicou-se a análise IPA por meios de questionários. O propósito desta análise é identificar, sob a perspectiva dos clientes, os fatores mais importantes e o desempenho da empresa em relação a eles. Foram elaborados dois questionários: um direcionado à avaliação dos clientes com relação a importância dos fatores competitivos identificados; e o outro tendo como foco a avaliação destes clientes sob o desempenho da empresa Alfa nestes fatores. Cada pergunta de ambos os questionários estava associada a uma escala do tipo Linkert de cinco pontos, usualmente empregadas neste tipo de pesquisa. Após a aplicação da análise IPA, fezse uso da Matriz de correlações a fim de realizar uma análise das correlações entre os fatores levantados, de modo a auxiliar no processo decisório da empresa.

- Etapa III: foi desenvolvido um sistema de indicadores com foco operacional, para que os colaboradores do negócio possam acompanhar o desempenho das operações no decorrer dos próximos períodos, e favorecer a tomada de decisão dos responsáveis pela gestão da empresa. Para estipulação das metas, foram coletados dados do mês de dezembro de 2017, de modo a alimentar as variáveis destes indicadores, e consequentemente poder calculá-los. Através dos resultados deste indicador para o período, os colaboradores da empresa puderam estipular as metas para 2018. Foi elaborado um plano de ação, por meio da técnica 
$5 \mathrm{~W} 2 \mathrm{H}$, que contém um conjunto de propostas de ações a serem implementadas.

Após definida todas as etapas contidas na estrutura metodológica proposta, faz-se necessário identificar a população a ser investigada, bem como a amostra que representa esta população.

\subsection{Tamanho da amostra}

A amostra selecionada foi classificada em não probabilística e do tipo amostras por acessibilidade, que se expressa com menos rigor em relação a outros tipos de amostragem em que não há necessidade de tratamento estatístico (PRADANOV; FREITAS, 2013). Este tipo de amostra é comumente utilizado em pesquisas exploratórias.

Como todos os colaboradores, exceto o diretor, entraram na empresa Alfa no ano analisado, foi possível verificar que neste período 65 clientes foram atendidos, sendo esta a população a ser utilizada para aplicação da análise IPA. De acordo com Kasmier (2007), a população corresponde ao total de indivíduos e ou objetos dos quais necessitam ser obtidos determinadas informações.

Inicialmente, a aplicação da análise IPA consistiu, na aplicação de questionários devidamente elaborados. Após a elaboração dos questionários, todos os clientes foram devidamente informados através de ligações telefônicas sobre a importância da aplicação deste questionário, e também houve a solicitação da permissão para envio dos mesmos via Google forms.

Este processo ocorreu entre o início de dezembro até o final de janeiro do ano analisado. Vinte questionários foram respondidos, o que representa uma taxa de retorno de $30,77 \%$, sendo essa a amostra do estudo.

\section{RESULTADOS E DISCUSSÃO}

\subsection{Mapeamento de processos}

Através do software Bizagi Process Modeler, foi possível mapear o processo geral da prestação dos serviços por parte da empresa Alfa. A Figura 6 mostra o 
mapeamento do processo de prestação de serviços da empresa Alfa, utilizando a notação BPMN.

A Figura 6 mostra o processo geral de prestação de serviço para a empresa Alfa. Neste processo geral, há um total de nove pontos de decisão, sendo que apenas quatro destes são decisões a serem tomadas por parte do cliente, e dois dentre estes consistem em prosseguir ou não com a prestação de serviços pela empresa. Isso implica, que as atividades anteriores a estes dois pontos podem influenciar na tomada de decisão do cliente, ou seja, o bom desempenho destas atividades pode levar o cliente a prosseguir com os serviços da empresa. Um brainstorming foi realizado com os colaboradores da empresa Alfa, de modo a identificar quais aspectos os clientes observam nas atividades anteriores a cada ponto de decisão pelo qual avaliam a satisfação com relação a prestação do serviço.

Os seguintes aspectos foram levantados: preço de orçamentos; facilidade de acesso aos serviços; capacidade de desenvolver novos serviços; nível de atendimento; rapidez com que o projeto foi elaborado; cumprimento do prazo prometido; conformidades; cumprimento dos prazos prometidos, rapidez na execução dos serviços, nível de conformidade entre o projeto e os serviços executados, percepção de aparência de engajamento, conhecimento e habilidades dos funcionários, visual dos equipamentos e aparência dos funcionários, disponibilidade em executar os serviços no período solicitado pelo cliente, preço dos serviços, capacidade da empresa em executar o solicitado, bem como lidar com imprevistos. 
Figura 6 - Processo de prestação de serviço para a empresa Alfa

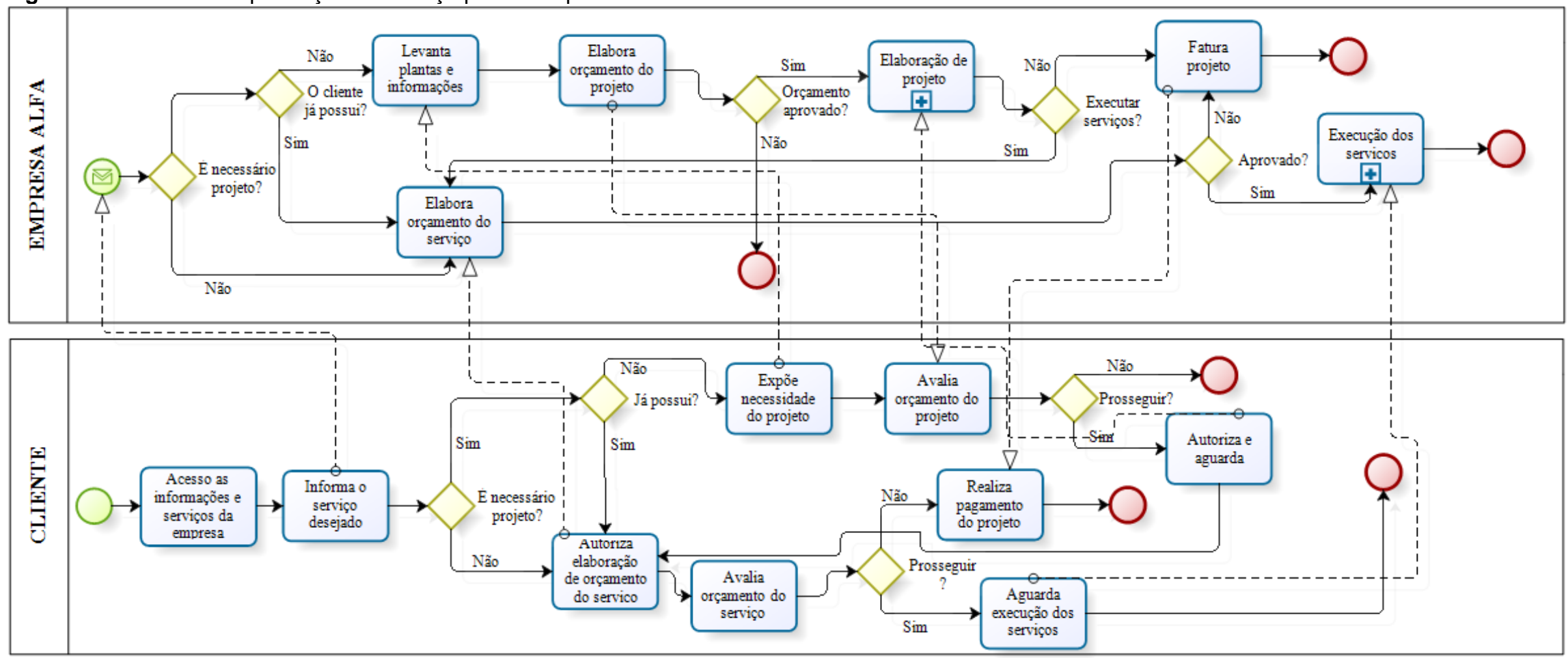

Fonte: $\mathrm{O}$ autor 


\subsection{Conversão dos objetivos de desempenho em fatores competitivos}

Cada dimensão ou objetivo operacional pode e deve ser fragmentado em diversos fatores, considerados competitivos, pois possibilitam agregar algum tipo de valor para os clientes ou consumidores. O Quadro 2 mostra os fatores competitivos, que representam cada objetivo de desempenho identificados para os serviços da empresa. A identificação destes fatores ocorreu por meio de um processo comparativo entre os aspectos mencionados no mapeamento do processo geral dos serviços da empresa com os fatores de desempenho em serviços descritos pelos autores Johnston e Clark (2002) e Corrêa e Caon (2002). Esta adaptação forneceu um total de 17 fatores competitivos a serem avaliados na empresa.

Quadro 2 - Objetivos de desempenho e fatores competitivos em serviços

\begin{tabular}{|c|c|c|}
\hline Objetivo & Fator & Descrição \\
\hline Confiabilidade & Confiabilidade no prazo & $\begin{array}{l}\text { Capacidade da empresa em entregar os serviços } \\
\text { dentro do prazo prometido. }\end{array}$ \\
\hline \multirow{7}{*}{ Qualidade } & Estética e limpeza & $\begin{array}{l}\text { Visual de instalações e equipamentos, aparência dos } \\
\text { funcionários, limpeza e organização do ambiente. }\end{array}$ \\
\hline & Conforto e Segurança & $\begin{array}{l}\text { Capacidade de fornecer conforto físico, além de } \\
\text { proporcionar ambiente seguro para os clientes e seus } \\
\text { bens. }\end{array}$ \\
\hline & Atendimento/Empatia & $\begin{array}{l}\text { Capacidade dos funcionários em proporcionar } \\
\text { interesse pelo cliente, bem como simpatia, paciência } \\
\text { educação durante o contato com o cliente, e ainda, a } \\
\text { habilidade de tornar o ambiente agradável. }\end{array}$ \\
\hline & Conformidade & $\begin{array}{l}\text { Capacidade da empresa em fornecer produtos e } \\
\text { serviços atendendo aos requisitos técnicos, pré- } \\
\text { estabelecidos e os prometidos aos clientes. }\end{array}$ \\
\hline & $\begin{array}{l}\text { Competência dos } \\
\text { funcionários }\end{array}$ & $\begin{array}{l}\text { Consiste no nível de conhecimento sobre as } \\
\text { atividades a serem desenvolvidas, execução correta } \\
\text { de procedimentos e orientação ao cliente. }\end{array}$ \\
\hline & Comprometimento & $\begin{array}{l}\text { Nível de engajamento dos funcionários em suas } \\
\text { atividades. }\end{array}$ \\
\hline & Acesso & $\begin{array}{l}\text { Facilidade em obter os serviços, o que inclui diversos } \\
\text { canais de acesso, e clareza das informações contidas } \\
\text { nos mesmos. }\end{array}$ \\
\hline Flexibilidade & Mix de serviços & Variedade de serviços e bens oferecidos aos clientes. \\
\hline \multirow{3}{*}{ Flexibilidade } & Nível de customização & $\begin{array}{l}\text { Capacidade da empresa na modificação de seus } \\
\text { serviços conforme necessidades dos clientes. }\end{array}$ \\
\hline & Flexibilidade na entrega & $\begin{array}{l}\text { Capacidade da empresa em atender ou modificar os } \\
\text { prazos de entrega diante de imprevistos, bem como } \\
\text { evitar e mitigar os mesmos. }\end{array}$ \\
\hline & Disponibilidade & $\begin{array}{l}\text { Capacidade da empresa em dispor de pessoal, } \\
\text { instalações e equipamentos para execução dos } \\
\text { serviços quando solicitado pelos clientes. }\end{array}$ \\
\hline
\end{tabular}


Quadro 3 - Objetivos de desempenho e fatores competitivos em serviços

\begin{tabular}{|c|c|l|}
\hline Objetivo & \multicolumn{1}{|c|}{ Fator } & \multicolumn{1}{c|}{ Descrição } \\
\hline \multirow{6}{*}{ Velocidade } & $\begin{array}{c}\text { Atendimento em } \\
\text { horário não } \\
\text { convencional }\end{array}$ & $\begin{array}{l}\text { Proporcionar serviços, produtos, soluçães e informações } \\
\text { aos clientes fora do horário de expediente. }\end{array}$ \\
\cline { 2 - 3 } & Inovatividade & $\begin{array}{l}\text { Capacidade da empresa em desenvolver novos } \\
\text { serviços, ou incluir produtos inovadores em seus } \\
\text { serviços. }\end{array}$ \\
\cline { 2 - 4 } & Rapidez & $\begin{array}{l}\text { É a capacidade da empresa em fornecer os serviços e } \\
\text { seus produtos, em um tempo menor que dos } \\
\text { concorrentes. }\end{array}$ \\
\hline Custo & Preço & $\begin{array}{l}\text { Corresponde a percepção de tempo por parte do cliente, } \\
\text { desde o pedido do serviço até a entrega do mesmo. }\end{array}$ \\
\hline Valor pago pelo bem ou serviço fornecido.
\end{tabular}

Fonte: Adaptado de Corrêa e Caon (2002); Johnston e Clark (2002); Paiva, Carvalho Júnior e Fensterseifer (2004); Slack, Chambers e Johnston (2009)

O termo "inovatividade" foi descrito por Paiva, Carvalho Júnior e Fensterseifer (2004) como um objetivo de desempenho. Neste estudo, a inovatividade foi inserida como um fator competitivo, que contribui para o objetivo flexibilidade. procedimento seguinte consiste em identificar a importância desses fatores para os clientes da empresa e o desempenho da empresa em cada fator. Assim será possível priorizar os fatores de modo a fornecer um breve diagnóstico operacional, além de favorecer na elaboração de métricas de desempenho.

\subsection{Análise de importância-desempenho}

Por meio da análise IPA foi possível identificar a importância de cada fator para os clientes da empresa e o desempenho da empresa nestes mesmos fatores. Assim, o diretor da empresa, junto com todos os colaboradores, poderá estabelecer um conjunto de ações embasadas na análise IPA com o propósito de melhorar suas operações. A Tabela 1 mostra os valores médios de importância e desempenho dos fatores anteriormente descritos, bem como a diferença entre a importância atribuída a cada fator e o desempenho da empresa nestes. 
Tabela 1 - Valores de importância e desempenho médios para os fatores competitivos

\begin{tabular}{cccc}
\hline Fatores & Importância & Desempenho & $\begin{array}{c}\text { (Importância - } \\
\text { Desempenho) }\end{array}$ \\
\hline $\begin{array}{c}\text { Conformidade } \\
\text { Competência dos }\end{array}$ & 4,950 & 4,800 & 0,150 \\
funcionários & 4,950 & 4,650 & 0,300 \\
Confiabilidade no & & & 0,250 \\
$\quad$ prazo & 4,850 & 4,600 & 0,150 \\
Conforto e & 4,850 & 4,700 & 0,050 \\
segurança & & & 0,450 \\
$\quad$ Nível de & 4,750 & 4,700 & 0,000 \\
customização & 4,750 & 4,300 & 0,050 \\
$\quad$ Preço & 4,700 & 4,700 & 0,200 \\
Atendimento/empatia & 4,700 & 4,650 & 0,100 \\
Comprometimento & 4,700 & 4,500 & 0,100 \\
Disponibilidade & 4,650 & 4,550 & 0,000 \\
Acesso & 4,550 & 4,450 & 0,050 \\
Estética e limpeza & 4,550 & 4,550 & $-0,050$ \\
Rapidez & 4,550 & 4,500 & 0,000 \\
Espera & 4,450 & 4,500 & $-0,200$ \\
Flexibilidade na & 4,400 & 4,400 & $-0,450$ \\
entrega & 4,200 & 4,400 & \\
Mix de serviços & & & \\
Inovatividade & 4,550 & \\
Atendimento em & 4,100 & & \\
horário não & & & \\
convencional & & &
\end{tabular}

Fonte: $\mathrm{O}$ autor

A Tabela 3 está organizada na ordem decrescente de importância atribuída pelos clientes respondentes. Percebe-se que todos os fatores estão entre a escala importante e muito importante, o que é de certa forma previsto, já que a aplicação da análise IPA, não exclui a presença da tendenciosidade por parte dos clientes. Segundo Paiva, Carvalho Júnior e Fensterseifer (2004), pesquisas de levantamentos de importância de critérios ou fatores estão sujeitas a avaliação tendenciosa de achar que tudo ou todos são muito importantes para o bom desempenho do serviço. As modificações realizadas na análise IPA, como uso dos erros padrão e médias globais, permitem realizar uma análise mais rigorosa quando comparada com esta metodologia tradicional.

A empresa apresenta desempenho satisfatório nos demais fatores. Apesar de não haver resultados preocupantes em primeira análise, faz-se necessário uma análise mais rígida para favorecer o planejamento da empresa, bem como a discussão posterior destes resultados e dos indicadores quantitativos que serão apresentados. O método IPA permite realizar uma análise bastante rígida, mesmo 
em cenários aparentemente positivos, de modo a direcionar a empresa a buscar a excelência em suas operações.

Para gerar a matriz de importância-desempenho, além das médias de importância e desempenho e dos erros padrão, é necessário transladar os eixos, ou seja, encontrar o ponto em que os dois eixos de interceptam, e assim delimitam as quatro áreas que compõem a matriz. Isto é obtido por meio das coordenadas geradas através das Equações (3) e (4). Estes valores são $G I(x)=4,626$ e $G D(x)=$ 4,559, para o eixo de importância e desempenho dos fatores, respectivamente. $O$ Quadro 3 mostra os fatores competitivos e as letras representativas a cada um destes, as quais serão utilizadas na plotagem da matriz de importância desempenho.

Quadro 3 - Correspondência entre fatores e letras

\begin{tabular}{|c|c|}
\hline Fatores & Letras representativas \\
\hline Conformidade & $\mathrm{A}$ \\
\hline Competência dos funcionários & $\mathrm{B}$ \\
\hline Confiabilidade no prazo & $\mathrm{C}$ \\
\hline Conforto e segurança & $\mathrm{D}$ \\
\hline Nível de customização & $\mathrm{E}$ \\
\hline Preço & $\mathrm{F}$ \\
\hline Atendimento/empatia & $\mathrm{G}$ \\
\hline Comprometimento & $\mathrm{H}$ \\
\hline Disponibilidade & $\mathrm{I}$ \\
\hline Acesso & $\mathrm{J}$ \\
\hline Estética e limpeza & $\mathrm{K}$ \\
\hline Rapidez & $\mathrm{L}$ \\
\hline Espera & $\mathrm{M}$ \\
\hline Flexibilidade na entrega & $\mathrm{N}$ \\
\hline Mix de serviços & $\mathrm{O}$ \\
\hline Inovatividade & $\mathrm{P}$ \\
\hline Atendimento em horário não convencional & $\mathrm{Q}$ \\
\hline
\end{tabular}

Fonte: $\mathrm{O}$ autor

A Figura 7 mostra a matriz importância-desempenho, na qual é possível verificar que ambos os eixos de desempenho (horizontal) e importância (vertical) foram transladados de acordo com as médias globais descritas anteriormente. Nesta Figura há também a exposição dos erros padrão para os valores médios de importância e desempenho dos fatores. 
Figura 7 - Matriz importância-desempenho com erros padrão

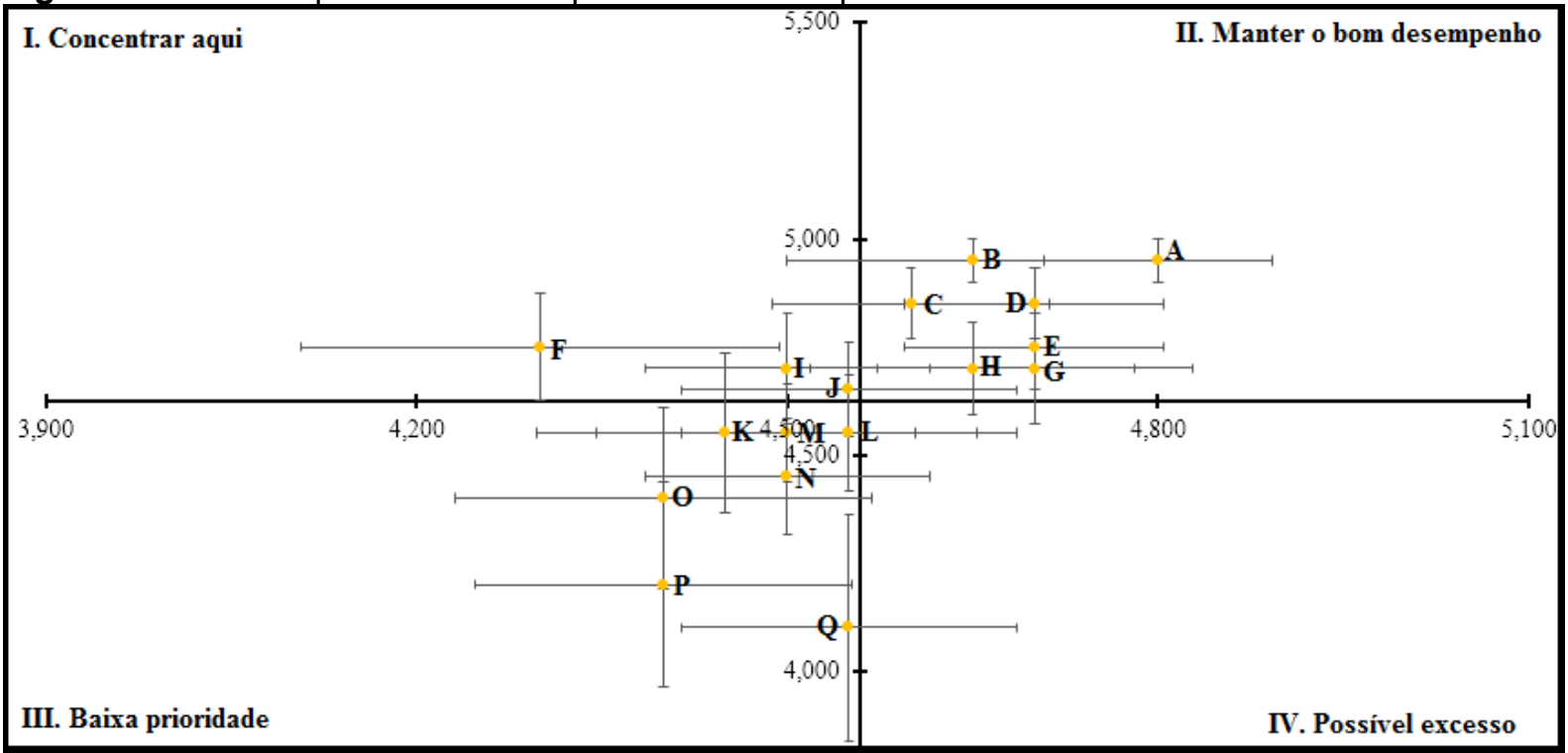

Fonte: $\mathrm{O}$ autor.

Os fatores Conformidade (A), Nível de customização (E), Inovatividade (P), Conforto e Segurança (D), Nível de customização e Preço (F) permanecem em seus quadrantes, mesmo levando em consideração o erro padrão. Ao analisar a localização dos demais fatores competitivos, utilizando seus respectivos erros padrão é perceptível que não se pode garantir a real localização dos mesmos. Destacam-se os fatores Estética e limpeza (K), Rapidez (L), Espera (M), Competência dos funcionários $(B)$ e Comprometimento $(H)$, que por estarem muito próximos dos eixos (fronteira), precisam ser avaliados com cautela. A Tabela 2 mostra os fatores e seus correspondentes quadrantes, de acordo com os erros padrão.

A Tabela 2 pode ser utilizada como ferramenta de auxílio em fases de planejamento e tomada de decisão na empresa, pois permite avaliar a localização dos fatores conforme variação referente ao desvio padrão. Por exemplo, ao idealizar uma situação em que se deseja atuar sob os fatores localizados no quadrante I, que são aqueles que devem ser priorizados, não se pode excluir os fatores $K, M, L, C, B$ e $\mathrm{H}$, pois os mesmos, devido o desvio padrão referente a média de importância, podem ser contabilizados a partir de uma perspectiva pessimista. 
Tabela 2 - Variação de quadrantes conforme desvio padrão

\begin{tabular}{|c|c|c|c|c|c|c|}
\hline \multirow[b]{2}{*}{ Fatores } & \multicolumn{3}{|c|}{ Desempenho } & \multicolumn{3}{|c|}{ Importância } \\
\hline & $\overline{G D}$ & $\begin{array}{c}\text { Erro } \\
\text { padrão }\end{array}$ & $\begin{array}{c}\text { Quadrantes } \\
\text { incertos }\end{array}$ & $\overline{G I}$ & $\begin{array}{c}\text { Erro } \\
\text { padrão }\end{array}$ & $\begin{array}{c}\text { Quadrantes } \\
\text { incertos }\end{array}$ \\
\hline$A$ & 4,800 & 0,092 & - & 4,950 & 0,050 & - \\
\hline B & 4,650 & 0,150 & I- II & 4,950 & 0,050 & - \\
\hline C & 4,600 & 0,112 & I- II & 4,850 & 0,082 & - \\
\hline D & 4,700 & 0,105 & - & 4,850 & 0,082 & - \\
\hline$E$ & 4,700 & 0,105 & - & 4,750 & 0,099 & - \\
\hline $\mathrm{F}$ & 4,300 & 0,193 & - & 4,750 & 0,123 & - \\
\hline G & 4,700 & 0,128 & - & 4,700 & 0,128 & II - IV \\
\hline $\mathrm{H}$ & 4,650 & 0,131 & I- II & 4,700 & 0,105 & II - IV \\
\hline I & 4,500 & 0,115 & I - II & 4,700 & 0,128 & I - III \\
\hline$J$ & 4,550 & 0,135 & I - II & 4,650 & 0,109 & $I-I I I$ \\
\hline K & 4,450 & 0,153 & III - IV & 4,550 & 0,185 & $I-I I I$ \\
\hline L & 4,550 & 0,135 & III - IV & 4,550 & 0,135 & $I-I I I$ \\
\hline$M$ & 4,500 & 0,154 & III - IV & 4,550 & 0,114 & $I-I I I$ \\
\hline$N$ & 4,500 & 0,115 & III - IV & 4,450 & 0,135 & - \\
\hline $\mathrm{O}$ & 4,400 & 0,169 & III - IV & 4,400 & 0,210 & - \\
\hline$P$ & 4,400 & 0,152 & - & 4,200 & 0,236 & - \\
\hline$Q$ & 4,550 & 0,135 & III - IV & 4,100 & 0,261 & - \\
\hline
\end{tabular}

Fonte: $\mathrm{O}$ autor.

\subsection{Análise de correlações dos fatores competitivos}

A aplicação da análise IPA é importante, pois permite realizar um diagnóstico operacional da empresa prestadora de serviços. Após todo o processo de diagnóstico, faz-se necessária a elaboração de um conjunto de recomendações para que a empresa possa melhorar o desempenho de suas operações. Para que este processo de elaboração de recomendações seja assertivo e seu resultado eficaz, é necessário verificar as relações entre os fatores competitivos.

Como a análise IPA identificou os fatores que devem ser priorizados (pertencentes ao quadrante I), possíveis recomendações embasadas num plano de ação serão elaboradas para que a empresa possa melhorar seu desempenho nestes fatores. Percebe-se que mudanças no desempenho de um determinado fator podem influenciar direta ou indiretamente o desempenho de outro, tornando-se essencial fazer uma análise de correlações destes fatores. Para isto, fez-se uso da matriz de correlações, comumente utilizada com uma das ferramentas que compõe a 
metodologia QFD, que pode ser visualizada na Figura a 8. A construção dessa matriz foi realizada por meio de uma reunião com todos os colaboradores, em que foi registrado a opinião de cada colaborador sobre as relações dos fatores.

Figura 8 - Matriz de correlações aplicada aos fatores competitivos

\begin{tabular}{|c|c|c|c|c|c|c|c|c|c|c|c|c|c|c|c|c|c|c|c|}
\hline Conformidade & $\hat{1}$ & $\mathrm{~A}$ & & & & & & & & & & & & \multicolumn{6}{|c|}{ Critérios } \\
\hline Competência dos funcionários & $\boldsymbol{t}$ & B & ++ & & & & & & & & & & & & sitiva & men & forte & & +2 \\
\hline Confiabilidade no prazo & $\hat{t}$ & $\mathrm{C}$ & - & ++ & & & & & & & & & & & sitiva & ment & fraco & & $+\quad 1$ \\
\hline Conforto e segurança & $\mathbf{t}$ & $\mathrm{D}$ & + & + & & & & & & & & & & & Ine: & cister & & & 0 \\
\hline Nível de customização & t & $\mathrm{E}$ & + & ++ & - & & & & & & & & & $\mathrm{Ne}$ & gativa & men & e fraco & & $\begin{array}{ll}- & -1\end{array}$ \\
\hline Preço & $\sqrt{7}$ & $\mathrm{~F}$ & + & + & + & & -- & & & & & & & & gativ & Imen & e forte & & $-\quad-2$ \\
\hline Atendimento/empatia & 刍 & G & & & & & & & & & & & & & & & & & \\
\hline Comprometimento & t & $\mathrm{H}$ & + & & ++ & + & + & + & + & & & & & & & & & & \\
\hline Disponibilidade & $\mathbf{t}$ & I & + & + & + & & & & & & & & & & & & & & \\
\hline Acesso & $t$ & $\mathrm{~J}$ & & & & + & & - & & & & & & & & & & & \\
\hline Estética e limpeza & $\mathbf{t}$ & $\mathrm{K}$ & & & & & & & & + & & & & & & & & & \\
\hline Rapidez & 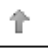 & $\mathrm{L}$ & & + & ++ & & - & + & & + & + & & & & & & & & \\
\hline Espera & $\overline{7}$ & M & & + & ++ & & - & + & & + & + & & & + & & & & & \\
\hline Flexibilidade na entrega & t & $\mathrm{N}$ & + & ++ & ++ & & & + & & + & + & & & + & & & & & \\
\hline Mix de serviços & t & $\mathrm{O}$ & & + & - & & - & - & & & - & & & - & - & & & & \\
\hline Inovatividade & $\mathbf{t}$ & $\mathrm{P}$ & & + & & & + & - & & + & & & & & & & + & & \\
\hline $\begin{array}{l}\text { Atendimento em horário não } \\
\text { convencional }\end{array}$ & $\Rightarrow$ & Q & + & + & + & & + & - & & & + & & & + & + & + & & & \\
\hline & & & $\mathbf{A}$ & $\mathrm{B}$ & $\mathbf{C}$ & D & $\mathbf{E}$ & $\mathbf{F}$ & $\mathbf{G}$ & $\mathbf{H}$ & I & $\mathbf{J}$ & $\mathbf{K}$ & $\mathbf{L}$ & $\mathbf{M}$ & $\mathbf{N}$ & 0 & $P$ & Q \\
\hline
\end{tabular}

Fonte: $\mathrm{O}$ autor

A Figura mostra a correlação entre todos os fatores de acordo com os colaboradores da empresa. Na segunda coluna é possível observar a presença de setas, sendo que estas expressam o desejo da empresa sob o desempenho de um determinado fator. As setas posicionadas verticalmente para cima representam a necessidade de aumentar a intensidade dos fatores, enquanto que as setas posicionadas verticalmente para baixo implicam no interesse em reduzir a intensidade de um determinado fator. Já a seta posicionada horizontalmente, representa a ausência de aumento ou redução da intensidade do fator.

Pode-se observar as relações entre as combinações de pares constituídos pelos fatores competitivos. Por exemplo, o fator preço está localizado no quadrante I da matriz IPA, mesmo considerando os valores de erro padrão. Este é um dos fatores que devem ser priorizados pela empresa, mas observa-se que caso obtenhase esta melhoria, esta poderá influenciar negativamente, com intensidade moderada, 
fatores como o Acesso, Mix de serviços, Atendimento em horário não convencional e Inovatividade; e com uma intensidade superior, afeta também o Nível de customização. Há influência positiva, a nível moderado, nos fatores Confiabilidade no prazo, Conformidade, Competência dos funcionários, Comprometimento, Flexibilidade na entrega, Disponibilidade e espera. Já os demais mantêm uma relação neutra, ou seja, não existe correlação entre eles.

Pode-se alcançar melhorias no desempenho do preço aumentado o desempenho dos fatores que mantém uma relação positiva com o fator preço. Outra alternativa para melhoria de desempenho no preço seria reduzir o desempenho dos fatores que afetam negativamente a melhoria do preço. Toda esta análise pode ser estendida para os demais fatores, sendo de grande utilidade para a tomada de decisão por parte da empresa.

\subsection{Sistema de Indicadores Operacional e Plano de Ação}

Após o diagnóstico da empresa no âmbito operacional por meio da aplicação da análise IPA, foi iniciado o processo de conversão dos fatores de desempenho em uma ou mais medidas. Como explicitado por Kaplan e Norton (1997), para gerenciar processos, primeiramente faz-se necessário buscar mensurá-los através de um conjunto de medidas que representem o comportamento dos mesmos. Este processo de conversão foi bastante simples: primeiramente utilizou-se de observação direta, cujo propósito era analisar as particularidades dos serviços e modos de execução. Em seguida, cada funcionário foi consultado juntamente com o diretor, sendo que foi discutido cada fator e a melhor forma de representa-los por meio de medidas. Foi possível identificar que alguns fatores não puderam ser convertidos de uma forma quantitativa, devido a sua natureza possuir caráter qualitativo.

Foi recomendado à empresa que ela realize semestralmente uma pesquisa de avaliação para todos os fatores identificados, onde que cada um destes terá como resultado uma determinada pontuação ou escore, por meio de perguntas, que servirá para avaliar o desempenho de todos os fatores sob a perspectiva do cliente. A Figura 9 explicita a estrutura dos indicadores operacionais do tipo quantitativos. 
Figura 9 - Estrutura dos indicadores de desempenho operacional quantitativo

\begin{tabular}{|c|c|c|c|c|c|c|c|c|}
\hline Objetivo & $\begin{array}{c}\text { Fator } \\
\text { competitivo }\end{array}$ & Indicador & ID & Descrição & Unidade & Propósito & Fórmula & $\begin{array}{l}\text { Periodo de } \\
\text { verificação }\end{array}$ \\
\hline Confiabilidade & $\begin{array}{c}\text { Confiabilidade na } \\
\text { entrega }\end{array}$ & $\begin{array}{l}\text { Índice de } \\
\text { entregas no } \\
\text { período }\end{array}$ & IEP & $\begin{array}{l}\text { Permite avaliar a } \\
\text { confiabilidade de entrega } \\
\text { dos serviços no periodo }\end{array}$ & $\%$ & Maximizar & $\begin{array}{l}\text { IEP }=\left[\left(\left(\mathrm{N}^{\circ} \text { de serviços entregues }\right.\right.\right. \\
\text { no periodo/ } \mathrm{N}^{\circ} \text { esperado de } \\
\text { serviços a serem entregues no } \\
\left.\text { período }))^{*} 100\right]\end{array}$ & Mensal \\
\hline \multirow[t]{2}{*}{ Qualidade } & Conformidade & $\begin{array}{l}\text { Nivel médio de } \\
\text { reclamações }\end{array}$ & NMRC & \begin{tabular}{|l|} 
Favorece o \\
monitoramento da \\
satisfação dos clientes \\
com a conformidade dos \\
serviços
\end{tabular} & $\begin{array}{c}\text { Reclamaçõ } \\
\text { es/ } \\
\text { Serviço }\end{array}$ & Minimizar & $\begin{array}{l}\text { IR }=\left(\mathrm{N}^{\circ} \text { de reclamações }\right) /\left(\mathrm{N}^{\circ} \text { de }\right. \\
\text { serviços entregues }+\mathrm{N}^{\circ} \text { de } \\
\text { serviços em execução })\end{array}$ & Mensal \\
\hline & $\begin{array}{c}\text { Conformidade e } \\
\text { Competências } \\
\text { dos funcionários }\end{array}$ & $\begin{array}{l}\text { Nivel médio de } \\
\text { retrabalho }\end{array}$ & NMR & $\begin{array}{l}\text { Possibilita Monitorar o } \\
\text { nivel de retrabalho }\end{array}$ & $\begin{array}{c}\text { Retrabalho } \\
\text { s/serviço }\end{array}$ & Minimizar & $\begin{array}{l}\mathrm{NMR}=\left(\mathrm{N}^{\circ} \text { de retrabalhos em }\right. \\
\text { serviços }) /\left(\mathrm{N}^{\circ} \text { de serviços em }\right. \\
\text { execução + } \mathrm{N}^{\circ} \text { de serviços } \\
\text { entregues })\end{array}$ & Mensal \\
\hline Flexibilidade & Disponibilidade & $\begin{array}{c}\text { Índice de } \\
\text { atendimento ao } \\
\text { período } \\
\text { solicitado }\end{array}$ & IAPS & $\begin{array}{l}\text { Capacidade da empresa } \\
\text { em prestar os serviços no } \\
\text { período solicitado pelo } \\
\text { cliente }\end{array}$ & $\%$ & Maximizar & $\begin{array}{l}\text { IAPS }=\left[\left(\mathrm{N}^{\circ} \text { de serviços iniciados }\right.\right. \\
\text { no período, conforme solicitados } \\
\text { pelos clientes }) /\left(\mathrm{N}^{\circ} \text { de serviços }\right. \\
\text { iniciados no periodo })]^{*} 100\end{array}$ & Mensal \\
\hline \multirow[b]{2}{*}{ Velocidade } & Rapidez & $\begin{array}{l}\text { Tempo médio de } \\
\text { execução }\end{array}$ & TME & $\begin{array}{l}\text { Permite acompanhar os } \\
\text { tempos de execução }\end{array}$ & $\begin{array}{l}\text { Horas/servi } \\
\text { ço }\end{array}$ & Minimizar & $\begin{array}{l}\text { TME = }\left[\left(\sum \text { tempos de execução }\right.\right. \\
\text { dos serviços entregues }) /\left(\mathrm{N}^{\circ} \text { de }\right. \\
\text { serviços entregues })]\end{array}$ & Mensal \\
\hline & Espera & $\begin{array}{l}\text { Tempo médio de } \\
\text { atravessamento }\end{array}$ & TMA & $\begin{array}{l}\text { Permite acompanhar os } \\
\text { tempos de } \\
\text { atravessamento }\end{array}$ & $\begin{array}{c}\text { Dias/serviç } \\
\circ\end{array}$ & Minimizar & $\begin{array}{l}\text { TMA }=\left[\left(\sum \text { tempos de }\right.\right. \\
\text { atravessamentos dos serviços } \\
\text { entregues }) /\left(\mathrm{N}^{\circ} \text { de serviços }\right. \\
\text { entregues })]\end{array}$ & Mensal \\
\hline \multirow[b]{2}{*}{ Custo } & \multirow[b]{2}{*}{ Preço } & $\begin{array}{l}\text { Margem de } \\
\text { Lucro Líquido }\end{array}$ & MLL & \begin{tabular}{|l|} 
Explicita a capacidade de \\
rentabilidade da empresa \\
em um determinado \\
período
\end{tabular} & $\%$ & Maximizar & $\begin{array}{l}\text { MLL = [(Lucro disponivel aos } \\
\text { acionistas)/(Receita de prestação } \\
\text { de serviços) }\end{array}$ & Mensal \\
\hline & & $\begin{array}{l}\text { Percentual } \\
\text { acima do } \\
\text { planejado }\end{array}$ & PAP & $\begin{array}{l}\text { Permite monitorar a } \\
\text { eficiência de aderência ao } \\
\text { planejamento }\end{array}$ & $\%$ & Minimizar & $\begin{array}{l}\text { IEFP }=\left[\left(\sum \text { tempos real de }\right.\right. \\
\text { execução dos serviços - } \\
\sum \text { tempos Planejado para a } \\
\text { execução dos } \\
\text { serviços }) /\left(\sum \text { tempos planejado }\right. \\
\text { para a execução dos } \\
\text { serviços })]^{\star} 100\end{array}$ & Mensal \\
\hline
\end{tabular}

Fonte: O autor 
Ao buscar levantar os dados e informações necessárias para o cálculo destes indicadores, verificou-se que a empresa não possuía nenhum banco de dados, exceto informações relativas ao âmbito financeiro. A partir disso, foi realizado um processo de orientação a todos os colaboradores da empresa, de modo a enfatizar a importância do uso de indicadores de desempenho e nos meios e métodos necessários para a coleta de dados. Contundo, o indicador Margem de lucro líquido pode ser utilizado tanto no contexto operacional quanto financeiro, sendo possível a coleta de dados para a realização do cálculo do mesmo, como mostra a Tabela 3.

Tabela 3 - Margem de Lucro Líquido para o ano analisado

\begin{tabular}{cc} 
Indicador & Valor para analisado \\
\hline MLL & $-12,26 \%$ \\
\hline
\end{tabular}

Fonte: $\mathrm{O}$ autor

Como pode ser observado por meio da Tabela 3 a empresa Alfa teve uma margem de lucro líquido negativa, o que implica num péssimo desempenho. Visando buscar direcionar a empresa na busca de melhorar este desempenho, no próximo ano, por meio das operações e áreas próximas como a financeira e mercadológica, foi elaborado um plano de ação. Este plano foi desenvolvido por meio da utilização da ferramenta 5W2H, como mostra a Figura 10. 
Figura 10 - Plano de ação

\begin{tabular}{|c|c|c|c|c|c|c|}
\hline & & $5 \mathrm{~W}$ & & & $2 \mathrm{H}$ & \\
\hline O quê? (What?) & Porque? (Why?) & Onde? (Where?) & Quem? (Who?) & Quando? (When) & Como? (How) & $\begin{array}{l}\text { Quanto custa? } \\
\text { (How much?) }\end{array}$ \\
\hline $\begin{array}{l}\text { Utilizar diferentes meios para } \\
\text { garantir o prazo de recebimento }\end{array}$ & $\begin{array}{l}\text { Muitos clientes, não cumprem os } \\
\text { prazos estabelecidos }\end{array}$ & $\begin{array}{l}\text { Formalização do acordo } \\
\text { de serviços }\end{array}$ & Administrador & \begin{tabular}{|} 
Apartir de 02 de Janeiro \\
de 2018
\end{tabular} & $\begin{array}{l}\text { Controle de notas fiscais. Envio de Boletos, assim } \\
\text { que o acordo de serviços for formalizado. } \\
\text { Elaboração de contratos. }\end{array}$ & - \\
\hline $\begin{array}{l}\text { Utilizar metodologias e } \\
\text { programas de compartilhamento } \\
\text { de informação e } \\
\text { acompanhamento dos serviços }\end{array}$ & $\begin{array}{l}\text { Para buscar melhorar a } \\
\text { comunicação entre Diretor, } \\
\text { administrador e demais funcionários }\end{array}$ & Empresa & Diretor & \begin{tabular}{|} 
Apartir de 02 de Janeiro \\
de 2019
\end{tabular} & $\begin{array}{l}\text { Utilizando programas gratuittos para controle de } \\
\text { projetos e serviços, de modo a compartilhar as } \\
\text { informações, e reativar metodologia de } \\
\text { comunicação. }\end{array}$ & - \\
\hline Realizar pesquisa de mercado & $\begin{array}{l}\text { Para identificar preços e práticas } \\
\text { acometidas no setores de atuação } \\
\text { da empresa }\end{array}$ & $\begin{array}{l}\text { Em toda a cidade de } \\
\text { Aracaju e algumas } \\
\text { cidades do interior de } \\
\text { Sergipe }\end{array}$ & Funcionários & $\begin{array}{l}\text { A partir de } 05 \text { de } \\
\text { fevereiro de } 2018\end{array}$ & $\begin{array}{l}\text { Utilizar técnica do falso cliente e aplicação de } \\
\text { questionários por meio de redes sociais e email }\end{array}$ & $\leq \mathrm{R} \$ 500,00$ \\
\hline $\begin{array}{l}\text { Redefinir identidades } \\
\text { organizacionais e explicitá-las }\end{array}$ & $\begin{array}{l}\text { Para disseminar a todos } \\
\text { stakeholders, de modo a afirmar a } \\
\text { atividade principal da empresa, bem } \\
\text { como motivar todos os } \\
\text { colaboradores } \\
\end{array}$ & $\begin{array}{l}\text { Escritório, site e redes } \\
\text { sociais }\end{array}$ & $\begin{array}{l}\text { Todos os } \\
\text { colaboradores }\end{array}$ & $\begin{array}{l}\text { A partir de } 19 \text { de } \\
\text { fevereiro de } 2018\end{array}$ & $\begin{array}{l}\text { Discutindo, por meio de uma reunião quais os } \\
\text { objetivos individuais e coletivos de todos os } \\
\text { colaboradores da empresa, bem como o que } \\
\text { pretendem fornecer aos cliente }\end{array}$ & - \\
\hline $\begin{array}{l}\text { Realizar controle financeiro } \\
\text { mensal }\end{array}$ & $\begin{array}{l}\text { Para monitorar com maior rigidez a } \\
\text { saúde financeira do negócio, além } \\
\text { de permitir obter dados mais } \\
\text { confiáveis para a formação dos } \\
\text { preços dos serviços }\end{array}$ & $\begin{array}{l}\text { Sistema de gestão da } \\
\text { empresa }\end{array}$ & Adminitrador & $\begin{array}{l}\text { A partir de } 19 \text { de } \\
\text { fevereiro de } 2018\end{array}$ & $\begin{array}{l}\text { Elaboração de demonstrativos financeiros, como } \\
\text { os demonstrativos de fluxo de caixa e } \\
\text { demonstrativo de resultado do exercício, além da } \\
\text { formalização de um sistema de indicadores } \\
\text { financeiros }\end{array}$ & - \\
\hline $\begin{array}{l}\text { Controle gerencial de custos e } \\
\text { despesas }\end{array}$ & $\begin{array}{l}\text { Permite maior confiabilidade de } \\
\text { dados para determinação do } \\
\text { markup e consequentemente para a } \\
\text { formação dos preços dos serviços }\end{array}$ & $\begin{array}{l}\text { Sistema de gestão da } \\
\text { empresa }\end{array}$ & $\begin{array}{l}\text { Administrador e } \\
\text { Diretor }\end{array}$ & $\begin{array}{l}\text { A partir de } 19 \text { de } \\
\text { fevereiro de } 2019\end{array}$ & $\begin{array}{l}\text { Realização de rateio de custos e despesas para os } \\
\text { diferentes tipos de serviços, e também a } \\
\text { consideração da depreciação dos equipamentos }\end{array}$ & - \\
\hline $\begin{array}{l}\text { Divulgar serviços de automação } \\
\text { residencial e predial }\end{array}$ & $\begin{array}{l}\text { Atrair consumidores deste tipo de } \\
\text { serviços, para aumentar as receitas } \\
\text { advinda destes }\end{array}$ & Em Aracaju-Se & $\begin{array}{l}\text { Todos os } \\
\text { colaboradores }\end{array}$ & $\begin{array}{c}\text { A partir de } 05 \text { de março } \\
\text { de } 2018\end{array}$ & $\begin{array}{l}\text { Divulgando informações sobre a empresa e seus } \\
\text { serviços em grupos, via rede social, agendas de } \\
\text { serviços, pafletagem, melhorias na interface do } \\
\text { site. }\end{array}$ & $\leq \mathrm{R} \$ 3.700,00$ \\
\hline $\begin{array}{l}\text { Focar a prestação dos serviços } \\
\text { de instalação elétrica apenas } \\
\text { para outras empresas }\end{array}$ & $\begin{array}{l}\text { Devido ao volume de serviços } \\
\text { demandado e altos valores de } \\
\text { orçamentos. }\end{array}$ & Em Aracaju-Se & O Diretor & \begin{tabular}{|} 
A partir de 01 de Julho de \\
2018
\end{tabular} & $\begin{array}{l}\text { Formação de parcerias com empresas } \\
\text { construtoras, outros fornecedores e profissionais } \\
\text { da construção civil. }\end{array}$ & A determinar \\
\hline
\end{tabular}

Fonte: $\mathrm{O}$ autor 
As propostas contidas no plano de ação estão relacionadas aos problemas relatados neste estudo. Por exemplo, há uma proposta de pesquisa de mercados para buscar analisar os preços praticados dos serviços de automação e de instalação elétrica. É recomendada também a redefinição das identidades organizacionais da empresa, bem como a realização de controles financeiros e de custos e despesas. Deve-se investir na divulgação dos serviços, principalmente os referentes a automação residencial, predial e industrial.

\section{CONSIDERAÇÕES FINAIS}

Por meio da técnica de mapeamento de processos e investigação literária, foi possível determinar os fatores que a empresa deve monitorar para acompanhar seu desempenho operacional. A utilização da técnica IPA permitiu realizar um diagnóstico operacional e expor os fatores em que a empresa precisa atuar com maior atenção no curto prazo. Entre estes, destaca-se o fator Preço, que mesmo considerando o erro padrão permanece no quadrante I, em que é necessária ação urgente. Já para o fator conformidade, a empresa deve continuar mantendo seu desempenho atual, visto que este foi o fator em que a empresa apresentou melhor desempenho. A elaboração da matriz de correlações será de grande importância durante o processo de acompanhamento e tomadas de decisão referente aos fatores.

Outro objetivo atingido foi a elaboração de um sistema de indicadores, caracterizado por métricas qualitativas e quantitativas. Este sistema não pôde ser validado devido à ausência de dados e informações que não são registrados pela empresa, para alimentação e plotagem destes indicadores. A validação poderá ocorrer futuramente, com o registro e a coleta de dados a serem feitas pela empresa e de acordo com as orientações repassadas durante o desenvolvimento deste estudo, em que propostas de melhorias poderão ser formuladas e implementadas. Caso ocorram flutuações destes indicadores, isto servirá de indício da funcionalidade deste sistema proposto.

Apesar de não haver grande aplicabilidade destes indicadores na avaliação do desempenho da empresa, ou mesmo comparação com os resultados da análise IPA, um destes indicadores forneceu grande contribuição. A margem de lucro líquido 
permitiu identificar que no ano analisado, a empresa obteve péssimo desempenho financeiro. Por meio de ferramentas da qualidade, foi possível identificar possíveis causas que ocasionaram este resultado negativo.

É preciso ressaltar que a implementação deste sistema não implica que os objetivos estratégicos serão atingidos. É necessária a elaboração de um plano de ação, que pôde ser elaborado devido a este estudo. Este plano de ação corresponde à efetivação de outro objetivo traçado no estudo, e servirá para a empresa como primeiras ações a serem tomadas para melhoria de sua estratégia de operações.

\section{REFERÊNCIAS}

BAGGIO, A.F.; BAGGIO, D.K. Empreendedorismo: conceitos e definições. Rev. de Empreendedorismo, Inovação e Tecnologia, v. 1, n. 1, p. 25-38, 2014.

https://doi.org/10.18256/2359-3539/reit-imed.v1n1p25-38

BALDAN, Roquemar de Lima; VALLE, Rogério; SILVA, Humberto Pereira da.

Gerenciamento de processos de negócios: BPM - Business Process Management. - 2 . ed. - São Paulo: Érica, 2007.

BRASIL. Lei Complementar no 123, de 14 de dezembro de 2006. 2006. Disponível em: http://www.planalto.gov.br/ccivil 03/leis/LCP/Lcp123.htm Acesso em: 10 out. 2017.

BRASIL. Lei Complementar no 155, de 27 de outubro de 2016. 2016. Disponível em: http://www.planalto.gov.br/ccivil 03/leis/LCP/Lcp155.htm Acesso em: 10 out. 2017.

CARPINETTI, L.C.R. Gestão de qualidade: conceitos e técnicas . São Paulo: Atlas, 2010.

CORRÊA, H.L.; CAON, M. Gestão de serviços: lucratividade por meio de operações e de satisfação dos clientes. São Paulo: Atlas, 2002.

DIAZ, S.L.V. Indicadores de desempenho e gestão empresarial. Porto Alegre: SEBRAE/RS, 2007.

FATOKI, Olawale. The Causes of the Failure of New Small and Medium Enterprises in South Africa. Mediterranean Journal of Social Sciences, v. 5, n. 20, p. 922-927, 2014. https://doi.org/10.5901/miss.2014.v5n20p922

FERREIRA, L.F.F.; OLIVA, F.L.; SANTOS, S.A.; GRISI, C.C.H.; LIMA, A.C. Análise quantitativa sobre a mortalidade precoce de micro e pequenas empresas da cidade de São Paulo. Gestão da produção, São Carlos, v. 19, n. 4, p. 811-823, 2012. Disponível em: http://www.scielo.br/pdf/gp/v19n4/a11v19n4.pdf . Acesso em: 08 dez. 2019. https://doi.org/10.1590/S0104-530X2012000400011

FREITAS, A.L.P.; MORAIS, A.S.C. Análise importância desempenho aplicada á avaliação da qualidade em serviços bancários. Florianópolis: Revista produção online, v. 12, n. 4, p. 1131-1161, 2012. https://doi.org/10.14488/1676-1901.v12i4.1016 
GEM. Empreendedorismo no Brasil 2015: relatório executivo. Disponível em:

http://www.bibliotecas.sebrae.com.br/chronus/ARQUIVOS CHRONUS/bds/bds.nsf/c6de907f e0574c8ccb36328e24b2412e/\$File/5904.pdf Acesso em: 08 dez. 2016.

GIL, A. C. Métodos e técnicas de pesquisa social. 6. ed. São Paulo: Atlas, 2008.

IBGE. COORDENAÇÃO DE SERVIÇOS E COMÉRCIO. As micro e pequenas empresas comerciais e de serviços no Brasil 2001. Rio de Janeiro: IBGE, 2003. Disponível em:

http://www.ibge.gov.br/home/estatistica/economia/microempresa/ Acesso em: 12 dez. 2016.

IBGE. Pesquisa anual de serviços 2015 - PAS. 2015. Disponível em:

https://biblioteca.ibge.gov.br/visualizacao/periodicos/150/pas 2015 v17 informativo.pdf

Acesso em: 05 out. 2017.

IBPT. Causas de desaparecimento das micro e pequenas empresas. 2013, p. 1-4.

Disponível em:

http://www.ibpt.com.br/img/uploads/novelty/estudo/701/CausasDeDesaparecimentoDasMicr osEPequenasEmpresas.pdf Acesso em: 08 dez. 2016.

JOHNSTON, Robert; CLARK, Graham. Administração de operações de serviço. São Paulo: Atlas, 2002.

KAPLAN, R.S.; NORTON, D.P. A estratégia em ação: balanced scorecard. Rio de Janeiro: Campus, 1997.

KASMIER, L. Estatística aplicada à administração e economia. 4 ed. Porto Alegre: Bookman, 2007.

LISBOA, Maria da Graça Portela. Design e qualidade: uma análise do processo produtivo de ourivesaria. 2009. 161f. Dissertação (Mestrado em Engenharia da Produção) -

Universidade Federal de Santa Maria, Santa Maria, 2009.

MARTILLA, J. A., JAMES, J. C. Importance-performance analysis. Journal of

Marketing, n. 9, p. 41-77, 1977. https://doi.org/10.2307/1250495

PAIVA, Ely Laureano; CARVALHO JÚNIOR, José Mário de; FENSTERSEIFER, Jaime Everaldo. Estratégia de produção e operações. Porto Alegre: Bookman, 2004.

PAVANI JÚNIOR, O.; SCUCUGLIA, R. Mapeamento e gestão por processos: BPM. São Paulo: M. Books do Brasil Editora Ltda, 2011.

PRADANOV, Cleber Cristiano; FREITAS, Ernani Cesar de. Metodologia do trabalho científico: métodos e técnicas da pesquisa e do trabalho acadêmico. 2. ed. Novo Hamburgo: Feevale, 2013. Disponível em: http://www.feevale.br/Comum/midias/8807f05a14d0-4d5b-b1ad-1538f3aef538/E-

book\%20Metodologia\%20do\%20Trabalho\%20Cientifico.pdf Acesso em: 21 maio de 2017.

RECEITA DA FAZENDA. O que é o simples nacional. Disponível em:

https://www8.receita.fazenda.gov.br/SimplesNacional/Documentos/Pagina.aspx?id=3

Acesso em: 07dez. 2016.

SEBRAE, UGE. Participação das micro e pequenas empresas na economia brasileira. Brasília: Sebrae, 2014. Disponível em: 
https://www.sebrae.com.br/Sebrae/Portal\%20Sebrae/Estudos\%20e\%20Pesquisas/Participac ao\%20das\%20micro\%20 \%20pequenas\%20empresas.pdf Acesso em: 12 dez. 2016.

SLACK, Nigel; CHAMBERS, Stuart; JOHNSTON, Robert. Administração da produção. 3. ed. São Paulo: Atlas, 2009.

VIEIRA, MARIO LÉDIO. A contribuição das micro e pequenas empresas para a redução da pobreza no brasil. Fortaleza: UFC, 2007. Disponível em:

http://repositorio.ufc.br/bitstream/riufc/5621/1/2007 dissert mlvieira.pdf. Acesso em: 09 dez. 2016.

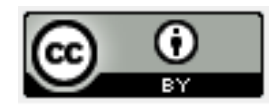

Artigo recebido em: 14/05/2020 e aceito para publicação em: 25/09/2020

DOI: http://dx.doi.org/10.14488/1676-1901.v20i3.4052 